\title{
Chemical and Biological Terrorism after Tokyo: Reassessing Threats and Response
}

\author{
Joseph F. Pilat Los Alamos National Laboratory, USA
}

$\mathbf{O}$ ne of the most important points made in Jonathan Tucker's interesting article appears in his concluding paragraph. He states that "although another large scale $\mathrm{C} / \mathrm{B}$ [chemical/biological] terrorist attack remains unlikely, the Tokyo subway incident has lowered the threshold for future disasters of this type." He goes on to say: "Given the potential cost in human lives and psychological trauma, the emergency threat warrants a significant U.S. national investment in the preparation of contingency plans, the training of medical personnel, and the stockpiling of relevant medications." Although Tucker's conclusions appear to me to be correct, and his assessment of the prospects for future terrorism are strongly implied throughout his article, he does not clearly and explicitly state his rationale for these conclusions. In fact, at the beginning of his article, he seemed to be heading in a different direction when he declared:

As the first large-scale terrorist incident involving a lethal chemical agent, it [the Tokyo subway gassing] weakened a long-standing psychological taboo and raised the spectre of more such incidents in the future. Lt. Gen. James Clapper, a former director of the Defense Intelligence Agency, has called the potential for terrorism involving mass-casualty weapons one of the "most nightmarish concerns" facing the U.S. and its allies.

Among the problems in dealing, or "coping," with this critical issue has been a tendency to hype the threat of nuclear, biological, and chemical (NBC) terrorism. Indeed,

Joseph F. Pilat is with the Nonproliferation and International Security Division of Los Alamos National Laboratory, Los Alamos, NM 87545, USA. He previously served in the Center for National Security Studies and the Strategic Analysis Group at Los Alamos. He was a special advisor to the Department of Energy's representative at the Third Review Conference of the Nuclear Nonproliferation Treaty, and served as representative of the Secretary of Defense to the Fourth NPT Review Conference and as an adviser to the U.S. Delegation at the 1995 NPT Review and Extension Conference. He is the author or editor of numerous books, including Bevond 1995: The Future of the NPT Regime (1990), and 1995: A New' Beginning for the NPT (1995). The views expressed by the author are his own, and do not necessarily reflect those of the Los Alamos National Laboratory, the University of Califomia, the Department of Energy, or any other agency of the United States Government. over the last 20 years, there have been times when NBC terrorism was expected to pose a clear and present threat, in the view of both academic and policy circles. The focus of these fears was nuclear terrorism, primarily driven by growing stockpiles of weapon-usable materials in civilian fuel cycles around the world. These fears were never realized, and until the Tokyo subway attack, no significant acts of NBC terrorism occurred. Nonetheless, many believed that NBC terrorism was inevitable and that it was only a question of time before a major incident occurred. From this perspective, the Tokyo attack was a confirmation of their sobering prediction.

And the use of nerve gas by a group that was also investigating biological and nuclear options has reinforced for many the inevitability of NBC terrorism. It is argued that the use of a chemical agent will inevitably lead to biological and nuclear terrorism because, in part, terrorist organizations will seek a full complement of NBC capabilities. The unprecedented use of such weapons by a person or organization, it is argued, moves the threat of NBC terrorism from the realm of theory to that of practice. It effectively ends the taboo on this particularly destructive form of terrorism.

Given the potential consequences of NBC terrorism, there is reason to heed the warnings of the Tokyo tragedy. But, to deal effectively with the threat, it is important to properly understand the Tokyo incident, and its implications.

First, the Tokyo incident claimed twelve lives; however tragic, this does not constitute mass destruction and therefore raises questions about what threshold was crossed by the action. That the terrorists apparently intended to kill more people should not be forgotten or underplayed. Yet, the fact that their intentions were not realized means that we have not yet experienced terrorism that brought about mass destruction.

Second, the use of a chemical agent does not necessarily mean that other weapons of mass destruction are more likely to be used by terrorists; in fact, it is increasingly recognized that chemical weapons are very different from nuclear and biological weapons in their capabilities. Their sociopolitical impact-their effects on politics in the United States and around the world-may differ as well for a world that has witnessed chemical attacks and threats in the two Gulf Wars and the Bhopal chemical accident in India.

Third, the public reaction was limited beyond Japan. Although there were widespread reactions of horror and 
revulsion to the attack, they were not on the scale that had been predicted for such an event. The Tokyo attack did not really lead to fundamental changes in the way the world is dealing with the threat, although the attack has sensitized publics and governments to the potential dangers of $\mathrm{C} / \mathrm{B}$ terrorism and spurred efforts in Japan and the United States, at least, to combat this threat. In Japan, for example, additional video surveillance in subway stations and upgraded fire department capabilities to analyze gases have been put into place, and large-scale gas escape drills have been conducted since the attack. There are reportedly lingering feelings of fear and uncertainty, and some criticism of the government's response to the attack.

Fourth, the group responsible may have been unique in combining scientific expertise, political-military connections, and wealth with an apocalyptic philosophy. Would all of these characteristics be necessary for an organization to effectively undertake C/B terrorism? Certainly they are important, and organizations that possess all of them are limited. How many other organizations would have similar capabilities?

And, finally, the police response in rounding up the organizers of the incident was efficient, and there does not appear to be a continuing threat from the group. The effectiveness of the Japanese response can only be judged after the trials of Aum's leader and other activists are completed, but there has not yet been a spate of copycat incidents, and the lesson to would-be perpetrators may be that $\mathrm{C} / \mathrm{B}$ terrorism can lead to the destruction of the organization that perpetrates it.

In this context, the meaning of the Tokyo attack is as yet unclear. A number of questions arise that are germane to its significance. To what extent has the Tokyo subway gassing enhanced the prospects for $\mathrm{C} / \mathrm{B}$ terrorism in the future? What is the profile of terrorists who might consider $\mathrm{C} / \mathrm{B}$ terrorism? On these grounds, how extensive is the threat? What are the parameters of the $\mathrm{C} / \mathrm{B}$ threat? Does the full continuum of possibilities, from the use of chemical and biological weapons to theft or sabotage of $\mathrm{C} / \mathrm{B}$ weapons or materials, have to be addressed?

Tucker's analysis sheds light on these questions. An important contribution is his discussion of "a new type of terrorist." Looking to the past, the objectives of political terrorist groups that have been operating since the late 1960s-especially ideological left-wing terrorists and national-separatists-do not appear consistent with the use of $\mathrm{C} / \mathrm{B}$ terrorism. The shift in terrorism over the last decade, and especially since the end of the Cold War, to actions by the ideological right, ethnic groups, religious fundamentalists, and single-issue terrorists has not yet resulted in fundamental changes in terrorist actions that would make future $\mathrm{C} / \mathrm{B}$ terrorism inevitable. To the extent that these groups are removed from the promotion of political causes and are pursuing such vague ends as revenge or ajocalyptic visions, the prospects of their turning to $\mathrm{C} / \mathrm{B}$ terrorism increase, but are by no means likely to define the shape of things to come.
Apocalyptic terrorists are the only ones to have undertaken a significant act of $\mathrm{C} / \mathrm{B}$ terrorism and may be the class of terrorists most likely to do so in the future.

In assessing the future prospects, Tucker brings up some critical political and technical barriers, which, although clearly eroding, are still operating in my view. Despite the recent events and trends, the prospects for widespread C/B terrorism are unclear, in large part because there remain technical and political obstacles to $\mathrm{C} / \mathrm{B}$ terrorism. Although the chemical and biological activities of Aum highlight the declining technological barriers to $\mathrm{C} / \mathrm{B}$ terrorism-which is also demonstrated in the nuclear sphere by reports of nuclear smuggling from the former Soviet Union-the fate of Aum may actually reinforce a key political barrier to $\mathrm{C} / \mathrm{B}$ terrorism.

Tucker's discussion of the remaining technical hurdles is excellent and goes far toward suggesting the difficulty of achieving the goal of mass destruction by terrorist groups or individuals. But his discussion of political barriers is not as well elaborated. With the exception of Aum Shinrikyo, terrorists may not have engaged in $\mathrm{C} / \mathrm{B}$ terrorism because there was little or no advantage to them from such acts. Mass destruction has not been an objective in itself for most terrorists, and this may even hold for the Aum sect. Japanese authorities reportedly believe that the Tokyo attack constituted a test and that the real objective of Aum Shinrikyo was to overthrow the government and the military (although this may have entailed large-scale use of chemical weapons). In any event, indiscriminate threats involving $\mathrm{C} / \mathrm{B}$ weapons have not often been made by terrorist groups. While terrorists may recognize the tremendous coercive power they might derive from the possession of these weapons, or nuclear (explosive or radiological) weapons, they may also recognize the high political risks of making $\mathrm{C} / \mathrm{B}$ threats.

What are the political risks? What negative reactions might terrorists expect to follow their use of $\mathrm{C} / \mathrm{B}$ agents or weapons to cause mass casualties? Among the reasons Tucker and others have noted, murder on a massive scale could be expected to provoke widespread condemnation, erode support among sympathizers, and cause severe governmental reactions. Historically, the terrorist organizations most likely to have resources, technical expertise, and the command and control capability that could allow them to undertake acts of $\mathrm{C} / \mathrm{B}$ terrorism are precisely those organizations that will most seriously weigh these political factors and could, under most conceivable circumstances, be expected to be deterred by them. The case of Aum offers a counterpoint of some significance, although even here the attack was haphazardly conducted in some respects.

The other aspect of $\mathrm{C} / \mathrm{B}$ terrorism is response. As Tucker rightly notes, whatever the likelihood of $\mathrm{C} / \mathrm{B}$ terrorism, its possibility is real, and after the Tokyo subway attack, improved responses are prudent. In considering responses, it will probably be necessary to seek to prevent, neutralize, or mitigate the most likely kinds of attacks rather than to attempt to defend against all possible terrorist scenarios. In 
the current political and budgetary climate, it is not possible to start and sustain a program based on worst-case scenarios that are, or will be seen to be, incredible.

$\mathrm{C} / \mathrm{B}$ attacks on the Capitol, the White House, the Pentagon, or other functioning or symbolic centers of government, along with attacks on the U.S. populace in subways, large office buildings, and the like, are the basis of most scenarios generated in governmental and academic circles. Prior to Aum Shinrikyo's gassing of a crowded Tokyo subway, these scenarios were purely speculative. The subway attack changed the picture.

It is clear that the United States and other democracies are, in principle, vulnerable to $\mathrm{C} / \mathrm{B}$ attacks and to other forms of terrorism. As suggested, basing a response on all possible vulnerabilities, however implausible, is likely to be counterproductive, creating public concerns without the possibility of addressing them adequately. If one looks to the Tokyo attack, what could have been done to prevent this tragic event? Clearly, without undermining the principles of democratic societies, there were significant limits on actions. But adequate intelligence, surveillance, and possibly intervention by the Japanese authorities was certainly possible, and might well have been effective.

Although vulnerabilities cannot be totally removed in democracies, effective counterterrorism strategies can be undertaken. Intelligence is the most important tool in combating $\mathrm{C} / \mathrm{B}$ terrorism, but export controls and monitoring, and various detection, interdiction, forensic, and mediation tools are critical to the fight. Protective measures in areas of high risk may also be very effective. More general civil defense preparedness is important and potentially effective in principle, but it is problematic. It is not clear that resources will be devoted to this task, or how accepting of such efforts the public would ultimately be.

Further analysis is needed of key issues, ranging from the prevention of $\mathrm{C} / \mathrm{B}$ acquisition and use to protection during and following an attack. What are the $\mathrm{C} / \mathrm{B}$ threats that should be fully taken into account in military. and civil planning processes? What approaches might be considered to deny access to potential threats (e.g., to centralize and protect agents and materials in use and storage, safeguards or treaty regimes, tagging/marking, etc.)? What are the prospects of success for denial approaches? What are the intelligence requirements for effectively countering $\mathrm{C} / \mathrm{B}$ proliferation and terrorism? Can these requirements be met at present? In the future? How should we create new intelligence capabilities to meet emerging threats? Are improvements in collection, analysis, and distribution needed and possible?

In terms of response planning, what capabilities and approaches might be applicable to $\mathrm{C} / \mathrm{B}$ terrorism? What national and international mechanisms currently exist to respond to $\mathrm{C} / \mathrm{B}$ incidents? Will these mechanisms be useful for responding to the emerging threat? What deficiencies can be identified? What approaches (policy, technical, training, etc.) hold promise of improving the situation? How critical is widespread civil defense? What new military roles could emerge? What technical means might be used to neutralize or interdict weapons or materials? What are the technical challenges we might confront? What operational challenges or obstacles can be expected? What are the key problems that will be encountered after a $\mathrm{C} / \mathrm{B}$ attack, and how might they be solved?

Tucker's full set of recommendations needs to be assessed in light of such questions and in the context of his recognition that "it is a sobering fact that no simple technical fix can completely eliminate the vulnerability of urban populations to the terrorist use of $\mathrm{C} / \mathrm{B}$ weapons." His recommendations are generally on the mark, in my view, especially those dealing with improvements in intelligence and lowcost civil defense preparedness. I might quibble over the relative priorities and importance he assigns to some of his recommendations, and, in the case of his suggestions on liability, their practicability. But his important article soberly assesses the threat and proposes a well-considered and realistic set of response options that will further the public debate on these issues. 